\title{
Using Student Reflections to Explore Curriculum Alignment
}

\author{
Marina Harvey ${ }^{1} \&$ Chris Baumann ${ }^{2}$ \\ ${ }^{1}$ Learning and Teaching Centre, Macquarie University, Australia \\ ${ }^{2}$ Faculty of Business and Economics, Macquarie University, Australia \\ Correspondence: Marina Harvey, Learning and Teaching Centre, Macquarie University, 2109, Australia. Tel: \\ 61-2-9850-9779. E-mail: marina.harvey@mq.edu.au
}

Received: August 21, 2012 Accepted: September 24, 2012 Online Published: October 31, 2012

doi:10.5539/ass.v8n14p9 URL: http://dx.doi.org/10.5539/ass.v8n14p9

\begin{abstract}
The concept of curriculum alignment is held as a guiding principle of good curriculum design in higher education. Curriculum alignment can be mapped using a variety of strategies and tools. This paper reports on a project that expands the horizons of curriculum review by applying a novel methodology, word clouds, to investigate the use of student reflections for exploring curriculum alignment.

Students, from Australia and Denmark, engaged in written reflections about their learning in a Business Brand Marketing subject. These reflections provide the data that is analysed for its alignment with the subject's learning outcomes. The word cloud analysis is found to be useful in providing evidence of curriculum alignment and indicators for directing deeper textual analysis.
\end{abstract}

Keywords: curriculum alignment, student reflection, word cloud analysis, learning

\section{Introduction}

The concept of curriculum alignment (Biggs \& Tang, 2007) is held as a guiding, research-based principle (Angelo, 2012) of good curriculum design in higher education. A curriculum which is intentionally designed (Kift \& Field, 2009) to be 'aligned' encourages student engagement in a deep, or at least deeper, approach to learning (English, Luckett \& Mladenovic, 2004) where all students are supported to use higher-order learning processes (Biggs, 2003). Curriculum alignment refers to an overt alignment between the course content, learning activities, teaching strategies and assessment of a subject which are in place to achieve the intended learning outcomes.

Alignment of curriculum can be explored and evaluated through a range of strategies and tools, many of which have evolved from, or been informed by, reflective practice. These strategies may span multiple reflective perspectives or lenses (after Brookfield, 1995) ranging from the autobiographical, collaborative and student perspective through to the learnings offered by the research literature. Examples of strategies for exploring curriculum alignment include individual reflection on the curriculum before, during and after teaching analogous to reflection for, in, and on action (after Schön, 1983); peer review of the curriculum or peer observation of teaching (Rowe, Solomonides \& Handal, 2010 and Bell, 2012) and the use of student reflections, evaluations, consultations and partnerships (Bols \& Freeman, 2011).

A range of tools have been developed to guide subject curriculum review with a focus on evaluating curriculum alignment (for example, the tasks offered by Biggs and Tang, 2011). Recent technologies for learning and teaching offer new possibilities for exploring curriculum alignment. This paper reports on a pilot project that applies a novel methodology, computer generated word clouds, to expand the horizons of curriculum alignment. It aims to do this by investigating the use of student reflections, on what students have learned, to explore the alignment of the curriculum with the intended learning outcomes. Learning outcomes "describe what a learner is expected to know, understand and be able to do after successful completion of a process of learning" (European Communities, 2009, p.11). The question posed therefore is: can new technologies be used as a methodology for providing evidence of an alignment between the intended learning outcomes of a subject and student reflections on student learning?

\section{Student Reflection for Learning}

As part of an extensive study on the use and role of student reflection in and for learning, this study uses data 
from two countries to investigate if there is an alignment between student reflections and intended learning outcomes for a key business/marketing subject (Brand Management) and if word clouds can be used to explore and evaluate curriculum alignment.

Student reflection is integral to the Brand Management curriculum that provides the case for this project. The students' engagement with reflection is specifically linked to a research assignment students undertake as a group activity. Reflection is a scaffolding strategy to enable students to make sense and meaning of their learning experiences (Rarieya, 2005) in relation to their research assignments. All students are required to document their reflection on learning as a part of their group research assignment, however, the submission of their summary reflections is optional. While the project assignment is assessed, the reflective writing is deliberately not assessed (Stewart \& Richardson, 2000).

Reflection literature reminds us of the need for a curriculum to clearly articulate intent, purpose, meaning and expectations (Boud and Knights, 1996; Bringle \& Hatcher, 1999) if we are to create a climate and context conducive for reflection. Further, transparent alignment (Harvey, Coulson, Mackaway \& Winchester-Seeto, 2010) of reflective practice with the curriculum is achieved as student reflection on the group research activity adheres to the principles for aligning reflection for learning for curriculum design (op cit). Firstly, the intent of reflective practice is clearly articulated through an alignment of the research project assignment with the reflective tasks; secondly through an articulation of expectations, in this subject (Brand Management) the students know that the reflective learning task is both voluntary and non-assessable; and finally the authenticity of the task is ensured as it is a work-integrated learning task. This curriculum can be considered to have a Work Integrated Learning (WIL) framework as the content, learning activities and the assessment (the group research project), "integrate theory with the practice of work within a purposefully designed curriculum" (Patrick, Preach, Pockneer, Webb, Fletcher \& Pretto, 2008, p. v).

The intent of the student reflection is focused through the use of a reflection template, a model developed specifically to scaffold the students' reflection on, and for, their learning. Students are introduced to the model and the roles of reflection in their first class by the research team. This model directs their reflection through four semi-structured questions on their learning on marketing, research, teamwork and areas for improvement. The reflective prompts of the model are:

\section{What have I learned about marketing/branding?}

What have I learned about conducting research?

What have I learned about teamwork during this assignment? and

What could I have done better?

The students' written reflections, in response to the above prompts, provide the rich textual data that is analysed for this project. As the fourth reflective prompt of "What could I have done better?" did not directly align with a learning outcome, but potentially with a graduate attribute, the data from this subset was not used for the purposes of this project. A critically reflective approach underpinned the conceptual framework for the methodology developed for this project. The definition of critical reflection that resonates with our learning and teaching philosophy is of

....a deliberate process when the candidate takes time, within the course of their work, to focus on their performance and think carefully about the thinking that led to particular actions, what happened and what they are learning from the experience, in order to inform what they might do in the future (King, 2002, p.2).

\section{Methodology}

Two student cohorts, studying in the same year, provide the data for this study. Both undergraduate cohorts of students were taught the same subject (Brand Management) by one of the authors. The larger cohort was based in a large metropolitan university in Australia and the second in a large metropolitan university in Denmark. Following human ethics approval from both institutions involved, all students were invited to participate in this project which was voluntary and did not require students to undertake any additional tasks or activities. The students' reflections would provide one significant lens to the project.

Brookfield's (1995) four reflective lenses: the lens of autobiography, of colleagues, of students and of the literature, provided the different data sources to enable triangulation, a method used to improve reliability (Silverman, 2000) and strengthen validity (Yin, 2011). The textual data used for this project therefore consisted of written student reflections, the autobiographical and collaborative reflections of the authors, together with the 
unobtrusive data of the subject outlines that provided the text on learning outcomes, and the lens of the research literature to inform the data analysis and interpretation.

Anonymous student reflections, focusing upon the four key reflection questions, were submitted with ethics consent forms. While all students were invited to submit their reflections about their learning, this participation was both voluntary and not graded. An overall response rate of $51 \%$ was attained. The response rate for the Danish cohort was higher (at 37 of the 50 students, or 74\%) than that for the Australian cohort (with 65 of the 150 students, or $43 \%$ ), resulting in a data set of 102 student respondents. All responses were entered into a spread sheet, which enabled easy uploading into the data analysis software utilised for this study, the NVivo content analysis software.

A large textual data set of the reflective responses by the 102 participating undergraduate students was achieved for this study. Responses from the two cohorts were aggregated, as the purpose of the analysis was an investigation of curriculum alignment, not of international comparisons. Prior to data aggregation, separate analyses were conducted by country cohort. The word frequency results were nearly identical, supporting our decision to aggregate the data.

The non-obtrusive data of the subject guide was used to identify the learning outcomes. These learning outcomes would represent the curriculum and its content. The student learning outcomes for this subject state that by the end of this subject students would be able to:

1) work effectively in teams to analyse and prepare presentations on brand management issues,

2) increase understanding of the important issues in planning branding strategies and in evaluating brand strategies, and

3) apply appropriate theories, models, and other tools used to make better branding decisions.

The methodology devised was aiming to expand the horizons of curriculum review. The steps developed for the process of using word clouds of students' reflections to explore curriculum alignment were:

1) conduct a word frequency analysis of the student reflection text,

2) present results as a word cloud, and

3) review the most frequent words for their alignment with the learning outcomes.

\section{Word Frequency Analysis in Research}

With the textual data sets prepared, a decision was needed regarding the method of analysis to be employed. The approach had to be compatible with the qualitative data and based on a method that had a proven validity and legitimacy. Content analysis, specifically word frequency analysis, has an established history (Krippendorff \& Bock, 2009).

Computer-assisted analysis of qualitative data (CAQDAS) provides the advantages of speed and rigour (Seale, 2000). The word frequency query function of NVivo, a content analysis software, was used to generate reports on the word frequencies (Krippendorff and Bock, 2009) of each of the three sets of student textual data, representing student responses to the three reflective prompts (on learning about marketing/branding; on research and on teamwork). NVivo also generates a visual representation of the results as a word or tag cloud (QSR International, 2010). In this visual representation of the data, the higher the word frequency, the larger and denser the font in the graphic that is produced.

The "with minimum length setting" was set at four letters to avoid frequent words such as I, we and do (QSR International, 2010). Display was set to report the 100 most frequent words. The "finding matches" command was set to "including synonyms" resulting in for example, the word "branding" representing the synonyms of: brand, branding and brands. The novel approach conceptualised for this project was that of using word clouds for curriculum review, exploring the patterns of word frequencies of student reflections to determine if there was any alignment between the reflections and the learning outcomes for the subject under investigation.

A search of the literature identified limited empirical evidence for the role or contribution of word frequency analysis, word tags / word cloud technology to research (Hearst \& Rosner, 2008). The majority of studies focused on the most useful placement of words or tags (Hearst \& Rosner, 2008; Lohmann, Ziegler \& Tetzlaff, 2009) however conjecture abounds on the applications of this relatively new technology.

The technology offers new ways of working with both quantitative and qualitative data. Cloud technology, by providing the means to analyse massive amounts of data (petabytes), makes the scientific method of hypothesise, model and test obsolete (Anderson, 2008). Petabytes allow us to say: "Correlation is enough." We can stop looking for models. We can analyse the data without hypotheses about what it might show. We can throw the 
numbers into the biggest computing clusters the world has ever seen and let statistical algorithms find patterns where science cannot" (p.109).

Although empirical evidence is not yet offered, the literature suggests that the two major types of visualisations, word frequency tag clouds and thematically organised word trees, may be useful in qualitative analysis for identifying core variables and theorising. They may also be used for validating research findings through exploration of observations and assumptions in researchers' reflective journals and checking for bias (Weisgerber $\&$ Butler, 2009). These collaborative uses do however present privacy and confidentiality issues preventing transcripts from being uploaded directly. Providing pseudonyms and obscure titles for data sets are methods suggested by Weisgerber \& Butler (2009) to overcome these issues. Other applications for the visualisations suggested by the authors are as a pedagogical tool to encourage academic discussion and as a research presentation tool to condense complex arguments and data into a manageable and engaging format. These applications were successfully realised through an investigation into graduate attributes and how they have changed over a fourteen year period (Bosanquet, Winchester-Seeto \& Rowe, 2010).

Whilst there is little published research on word tags or word clouds, the opportunities for collaborative group learning are many, suggesting possibilities for researchers to collaborate in data analysis, "encouraging diving deeply into the data set, finding patterns, challenging each other, making guesses about causal relationship, noting outlying data points, building on the findings of others and having fun at the same time" (Wattenberg \& Kris, 2006, p. 551). This project utilises this approach for its data analysis.

\section{Results and Discussion}

The data produced by the student reflections on what they have learned about marketing and branding, research and team work provide the focus for this paper. Results for each of these three reflective prompts is now presented and discussed.

\subsection{Reflecting on Marketing and Branding}

Two learning outcomes were subject specific, focusing upon branding strategies, theories and models. These learning outcomes anticipated that students would: "increase (their) understanding of the important issues in planning branding strategies and in evaluating brand strategies" and "apply appropriate theories, models, and other tools used to make better branding decisions". Student reflections on "what have I learned about marketing/branding?" were used to explore curriculum alignment.

A look at the word cloud produced using the student reflections on what they had learned about marketing presents a clear image of the importance of branding and marketing (Figure 1), with the frequency of these words being 99 and 75 respectively (Table 1). This image indicates an alignment between what the students have learned and the intended learning outcomes for this subject, suggesting the achievement of an aligned curriculum.

about actually advantages advertising analyse areas aspects awareness base

been before behaviour being both $\mathrm{OSO}$

business case company competitive complex concepts consider course crisis

customer decision definitions develop different each economy efficient emerging

equity every examples experience factors familiar firm from global good

have

i've idea impact Important increase issues keller lead

learned learnt life like loyalty maintain make management many

marketing

more much name order organisation

other people perspective plays points position practical previous process product range

related research role services should strategies successful than them theory

through tools topics understand unit unreadable very wants well what when world

Figure 1. Student reflections on marketing as a word cloud 
Table 1 . The top 10 words from student reflections on marketing

\begin{tabular}{ll}
\hline Word & Count \\
\hline Branding & 99 \\
Marketing & 75 \\
Have & 72 \\
Learned & 45 \\
Important & 29 \\
About & 28 \\
Different & 21 \\
More & 20 \\
Management & 20 \\
Much & 20 \\
\hline
\end{tabular}

Insights about the student learning of marketing and branding can be gleamed from the written reflections that provided these word frequencies. Verbatim quotes from the student reflections are provided to illustrate the context of the frequent words. Where quotes are provided, the student's country where they studied is provided. Student comments range from the appreciation of a general knowledge base, for example:

I have learned how marketing and branding really can be used in the real life. Furthermore I have learned how important marketing and branding is. Denmark

I've learned a lot about branding and the important role it plays for companies. Branding is what makes customers favour one company from another. Branding makes the difference and after this course I've become familiar with techniques companies use and I'm much more aware of the advertisement and techniques used in them. Denmark

To reflection upon their depth, breadth and currency of learning, with comments such as:

Learnt about current issues in marketing that have not been covered in other subjects - e.g. green marketing, branding of universities. Australia

I have learnt that marketing is a constantly evolving strategy. It never remains still or it will become irrelevant compared to competitors. Australia

I have learned to see the differences related to marketing and branding --> that branding is an important tool in gaining satisfied consumer and creating customer loyalty. Denmark

And reflection on specific skills gained:

With this being my $3 \mathrm{rd}$ and final year of studying marketing/branding I have developed a range of skills and a knowledge base of marketing concepts to fall back on. In this unit I have found these established concepts and skills have been taken to new level. By focusing on the one or two single areas, in my case within market research. I have gained a greater range of points of view, as well as how to deal with these concepts in a more practical context. Australia

Alignment with the learning outcome that students would be able to "apply appropriate theories, models, and other tools used to make better branding decisions" can be supported with the following examples of student reflections:

I was familiar with Aaker's theory before the start of the course, but I did learn to see branding from the perspective of Keller. Furthermore, I have learned more about the ways to maintain brand equity. Denmark [Aaker and Keller are the two leading textbook authors in the field of branding]

Mainly involves following: - Marketing strategy for emerging market. - MNCs trend to focus on emerging market and shift their business and investment. - Emerging market such as China/India etc. assist MNCs to increase their market share and growth. Australia

\subsection{Reflecting on Research}

Students undertook a group research project and reflected on their learning from that research experience. This aligns with the first learning outcomes of students being able to "work effectively in teams to analyse and 
prepare presentations on brand management issues". A viewing of the word cloud derived from students reflections on the reflective prompt for research (Figure 2) highlights the words research and learned, followed by key research related terms such as information (cited 27 times) and articles (with a frequency of 20, refer to Table2).

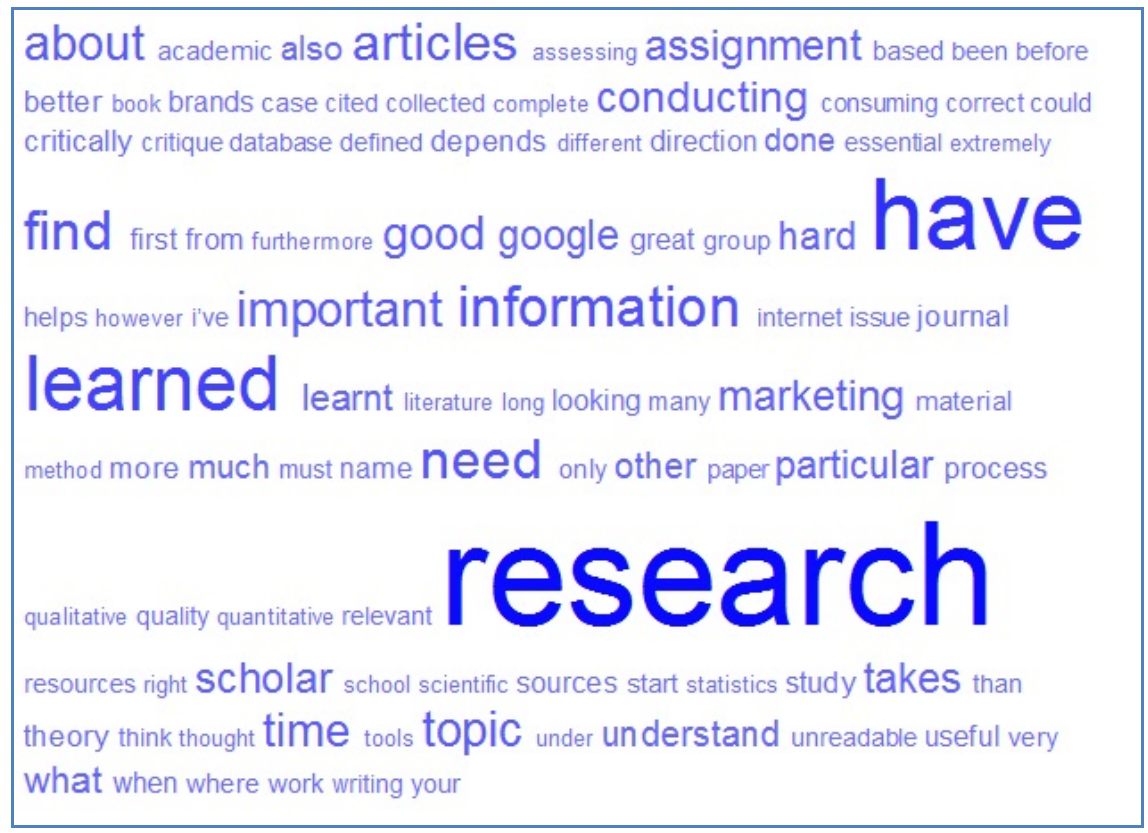

Figure 2. Student reflections on research as a word cloud

Table 2. The top 10 words from student reflections on research

\begin{tabular}{ll}
\hline Word & Count \\
\hline research & 77 \\
have & 61 \\
learned & 47 \\
information & 27 \\
find & 24 \\
need & 31 \\
articles & 20 \\
important & 21 \\
about & 20 \\
topic & 20 \\
\hline
\end{tabular}

Students reflected on the specific research skills they have developed:

I have learned about Google Scholar and to find hits [articles] that are heavily cited. Also I have learned to find more scientific journals than I could before. Denmark

Learnt how to write a literary review, i.e how to research background information about an author. Australia

How to effectively incorporate qualitative and quantitative research into projects. Critically analyse articles. Australia

How to find good quality articles and how to use databases right. Furthermore I learned a lot about citation. Denmark

I have learnt that research needs to be started early and be broader at the beginning - more focused 
towards the end. Scholarly articles provide far greater information. Australia

And on the value of these skills to their discipline of business/marketing:

Research is essential to understand expectations of consumers, the dynamic nature of market demands. Australia

\subsection{Reflecting on Teamwork}

The third student reflective prompt supported students to consider "what have I learned about teamwork during this assignment?" Student reflections as presented in the word cloud (Figure 3) provide a strong indication of an alignment between their reflections and the subject's learning outcome on working effectively in teams. The words: work, team and members are followed by "good" (Table 3).

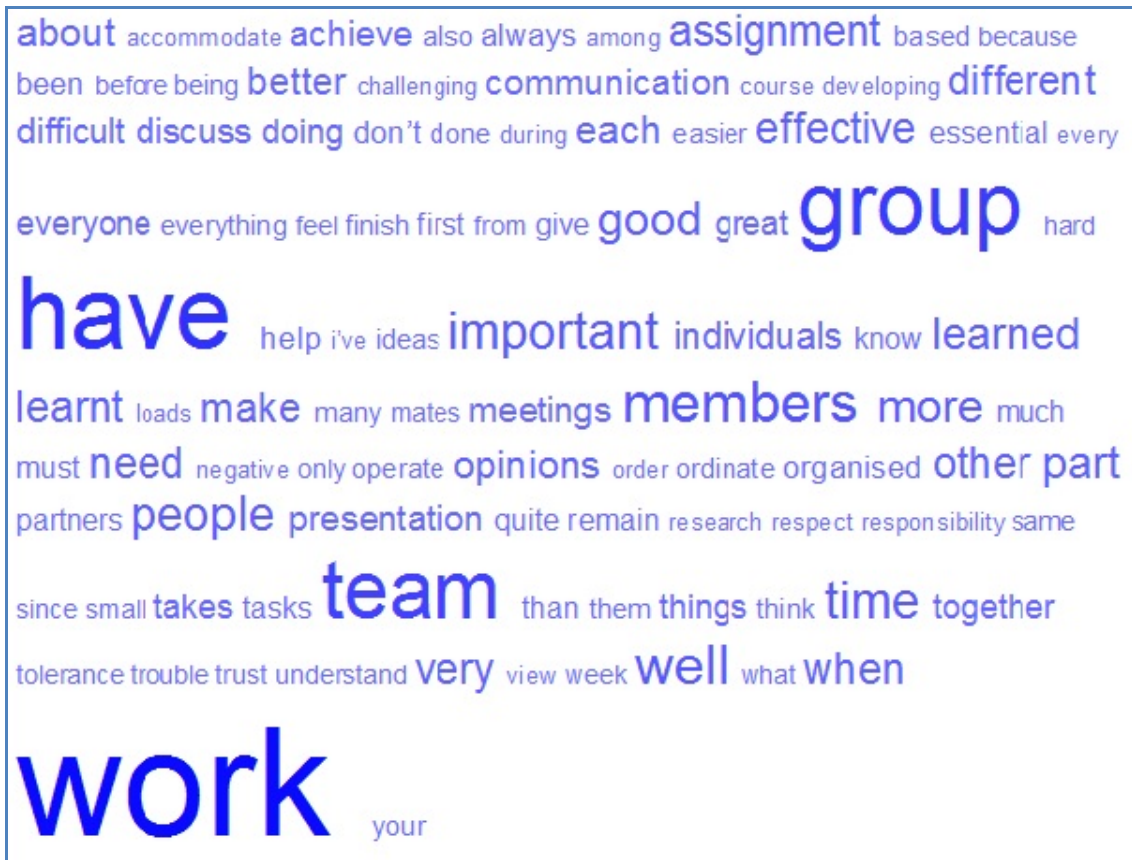

Figure 3. Student reflections on teamwork as a word cloud

Table 3. The top 10 words from student reflections on teamwork

\begin{tabular}{ll}
\hline Word & Count \\
\hline Work & 89 \\
Have & 62 \\
group & 41 \\
Team & 37 \\
good & 32 \\
members & 23 \\
Well & 27 \\
important & 20 \\
Time & 18 \\
people & 17 \\
\hline
\end{tabular}

Students reflected on many benefits of working in a team including:

I have learnt to negotiate effectively and to delegate tasks to appropriate students. For e.g., giving a highly research based task to students who were not comfortable with public speaking so they had a small speaking role. Australia 
You have to know your team mates, otherwise it can be difficult to work together. It takes time to make a team work and it helps if everybody is at the same level. The good thing about is that you get others view on your work and you get to discuss things. Denmark

Team is working together, discuss together. From the team work we know each other's and we have become good friends. Australia

Trust and understand what the other members of the group said. The points of view of each member is important and must be respected. Australia

It would be too simplistic to consider that the frequency of the word "good" with team work could be interpreted that team work in general was good. The students' writing reveals a more complex reasoning around the word "good", illustrated by:

I am a good leader. Been able to outsource the work and remain in control. Denmark

That it is a very good way to work with brand management. Denmark

We had a very good co-operation in our group. Time has been short to make the assignment but I think we have handled the stress quite well. Denmark

\section{Conclusion}

The use of word clouds, generated by student reflections, was explored as a means of expanding the horizons of curriculum review. Three sets of student reflective data were used, reflections about learning of their subject, on research and on teamwork. For each data set the word cloud indicated an alignment of student learning with the planned or intended curriculum. The word clouds, their accompanying word frequency tables and the student reflective text suggest an entrapment in a "web of consistency" (Ramsden, 2011), wherein the intended learning outcomes, subject content and student assessment, in this case a group research project, all are aligned to ensure optimal learning.

This study makes three distinct contributions. Firstly, it demonstrated that the methodology of analysing word clouds can be used as a research method to explore curriculum. The word clouds generated from the student reflections provided deep insights into the student experience of the course. Secondly, the student reflective prompts, developed for students to reflect on their learning on marketing, research and teamwork have been demonstrated to successfully elucidate student engagement with reflective practice. The student written reflections were related to the three reflective prompts. Finally, using data derived from the model of reflective prompts in tandem with a word cloud analysis allowed an exploration of curriculum alignment, which in the case of the subject under investigation was found to be high (i.e. strong alignment between the units' outcomes and student reports of learning). Given that we tested our student reflection prompt model and the word cloud approach in two distinct countries (Australia and Denmark) and found no apparent differences between the two countries in our analysis, we can conclude that the reflection prompt model and the word cloud approach work universally, at least in Western university settings.

The word cloud method has the advantage of very quickly providing a visual representation of word frequency, and a speedy and sharp account of student learning. Using this technique, one can quickly make an estimation of the level of curriculum alignment, providing important curriculum review feedback to the subject convenor. This method offers potential as a tool for expanding the horizons of curriculum review and as a pedagogical tool to encourage academic discussion (Weisgerber \& Butler, 2009). The word cloud technique can now benefit from emergent empirical studies that further explore the value and potential of the methodology and of the role of reflection for learning.

\section{References}

Anderson, C. (2008). The end of theory: The data deluge makes the scientific method obsolete. Wired, 16(7), 108-109.

Angelo, T. (2012). Designing subjects for learning: practical research-based principles and guidelines. In L. Hunt, \& D. Chalmers (Eds.), University teaching in focus. A learning-centred approach (pp.93-111). Camberwell: ACER press.

Bell, M. (2012). HERDSA Guide. Peer observation partnerships in higher education. Second Edition. Milperra: Higher Education Research and Developent Society of Australasia.

Biggs, J. (2003, April 13-17). Aligning teaching and assessing to course objectives. Paper presented at the Teaching and Learning in Higher Education: New Trends and Innovations Conference, University of Aveiro 
Biggs, J., \& Tang, C. (2007). Teaching for quality learning at university (3rd ed.). Maidenhead: Open University Press.

Biggs, J., \& Tang, C. (2011). Teaching for quality learning at university (4th ed.). Maidenhead: Open University Press.

Bols, A., \& Freeman, R. (2011). Engaging students in shaping their curriculum. Educational Development, 12(2), $5-9$.

Bosanquet, A., Winchester-Seeto, T., \& Rowe, A. (2010, July 6-9). Changing perceptions underpinning graduate attributes: A pilot study. In M. Devlin, J. Nagy, \& A. Lichtenberg (Eds.), Research and Development in Higher Education: Reshaping Higher Education, 33 (pp. 105-117). Melbourne.

Boud, D., \& Knights, S. (1996). Course design for reflective practice. In N. Gould, \& I. Taylor (Eds.), Reflective learning for social work: Research, theory and practice (pp. 23-34). Aldershot, Hants: Arena.

Bringle, R. G., \& Hatcher, J. A. (1999). Reflection in service-learning: Making meaning of experience. Educational Horizons, Summer, 179-185.

Brookfield, S. D. (1995). Becoming a critically reflective teacher. San Francisco, Jossey-Bass.

English, L., Luckett, P., \& Mladenovic, R. (2004). Encouraging a deep approach to learning through curriculum design. Accounting Education, 13(4), 461-488. http://dx.doi.org/10.1080/0963928042000306828

European Communities. (2009). European Credit Transfer and Accumulation System Users' Guide. Luxembourg: Office for Official Publications of the European Communities. Retrieved from http://ec.europa.eu/education/lifelong-learning-policy/doc/ects/guide_en.pdf

Harvey, M., Coulson, D., Mackaway, J., \& Winchester-Seeto, T. (2010). Aligning reflection in the cooperative education curriculum. Asia-Pacific Journal of Cooperative Education, 11(3), 137-152.

Hearst, M., \& Rosner, D. (2008). Tag clouds: Data analysis tool or social signaller? Proceedings of the 41st Annual Hawaii International Conference on System Sciences (HICSS 2008), 7-10 January 2008, 160-169. Waikoloa, Hawaii: HICSS.

Kift, S., \& Field, R. (2009) Intentional First Year Curriculum Design as a Means of Facilitating Student Engagement: Some Exemplars. In 12th Pacific Rim First Year in Higher Education (FYHE) Conference 2009, 29 June-2 July 2009, Townsville.

King, T. (2002). Development of student skills in reflective writing. Proceedings of the 4th World Conference of the International Consortium for Educational Development in Higher Education, 3-6 July, 2002. Retrieved from http://www.googlesyndicatedsearch.com/u/uniwa?q=terry+king

Krippendorff, K., \& Bock, M. A. (Eds.). (2009). The content analysis reader. Thousand Oaks: Sage.

Lohmann, S., Ziegler, J., \& Tetzlaff, L. (2009). Comparison of tag cloud layouts: Task-related performance and visual exploration. In T. Gross, J. Gulliksen, P. Kotze, L. Oestreicher, P. Palanque, R. Prates, et al. (Ed.), Human-Computer Interaction - INTERACT 2009, 12th IFIP TC 13 International Conference, Uppsala, Sweden, 24-28 August, 2009, Proceedings part 1. 5726, 392-404. Berlin: Springer.

Patrick, C-j., Peach, D., Pocknee, C., Webb, F., Fletcher, M., \& Pretto, G. (2008, December). The WIL [Work Integrated Learning] report: A national scoping study [Australian Learning and Teaching Council (ALTC) Final report]. Brisbane: Queensland University of Technology.

QSR International. (2010). NVivo9 Advanced. Conduct in depth analysis, discover patterns, visualize your data and share your findings. Author

Ramsden, P. (2011). Forward. In J. Biggs, \& C. Tang. (2011). Teaching for quality learning at university (pp. 17. 4th ed.). Maidenhead: Open University Press.

Rarieya, J. (2005). Promoting and investigating students' uptake of reflective practice: A Pakistan case. Reflective Practice Journal, 6(2), 285-294. http://dx.doi.org/10.1080/14623940500106518

Rowe, A., Solomonides, I., \& Handal, B. (2010). How to collaborate with peer observation. Learning from each other. North Ryde: Macquarie University. Retrieved from http://staff.mq.edu.au/public/download.jsp?id=50019

Schön, D. A. (1983). The reflective practitioner: how professionals think in action. New York: Basic Books.

Seale, C. (2000). Using computers to analyse qualitative data. In D. Silverman (Ed.), Doing qualitative research. 
A practical handbook (pp. 154-174). London: Sage.

Silverman, D. (2000). Doing qualitative research. A practical handbook. London: Sage. http://dx.doi.org/10.1080/713611443

Stewart, S., \& Richardson, B. (2000). Reflection and its place in the curriculum on an undergraduate course: Should it be assessed? Assessment \& Evaluation in Higher Education, 25(4), 369-380.

Wattenberg, M., \& Kriss, J. (2006). Designing for social data analysis. IEEE Transactions on visualization and computer graphics, 12(4), 549-557. http://dx.doi.org/10.1109/TVCG.2006.65

Weisgerber, C., \& Butler, S. (2009). Visualizing the future of interaction studies: Data visualization applications as a research, pedadogical, and presentational tool for interaction scholars. The Electronic Journal of Communication, 19(1-2). Rotterdam Jct., NY, USA: Communication Institute for Online Scholarship.

Yin, R. K. (2011). Qualitative research from start to finish. New York: The Guilford Press. 